\title{
Evaluation and Analysis of Traffic Flow at Signalized Intersections in Nicosia Using of SIDRA 5 Software
}

\author{
Shaban Ismael Albrka Ali*, Rifat Reşatoğlua \& Hudaverdi Tozan \\ Civil Engineering Department, Faculty of Civil and environmental Engineering, Near East University, North Cyprus, Turkey
}

\begin{abstract}
Traffic congestion on road networks and signalized intersections have posed significant problems worldwide. One of the significant ways to reduce traffic congestion in cities is by improving the public transportation system. Therefore, it is essential to use advanced software tools to ensure that the current system can be controlled and evaluated. This study was aimed at assessing and analysing the performance of traffic flow at signalized intersections and roundabouts at peak hours in the city of Nicosia (northern part of the island) using the SIDRA INTERSECTION 5 software. It was also aimed at comparing the performance of traffic flow during the morning and evening peak hours at four intersections and two roundabouts. The parameters used to assess the performance of the traffic flow were the level of service, delays and delayed travel speed, performance index, operating cost, fuel consumption, and carbon dioxide emission. It was found that the SIDRA INTERSECTION software was able to give an estimate of the current situation of traffic flow in the city. The results showed that the level of service was low, resulting in low speeds and lots of delays during the evening and morning peak hours. The delay was up to 9318.9 seconds and the fuel consumption was nearly 1431.6 lit/h, while the $\mathrm{CO}_{2}$ emission was up to $3594.7 \mathrm{~kg} / \mathrm{h}$.
\end{abstract}

Keywords: SIDRA intersection 5; traffic congestions; signalized intersections; roundabouts and level of service

\section{INTRODUCTION}

Road traffic congestion comprises of several complex procedures and incorporates numerous components cooperating simultaneously. In such a severe problem condition a simulation modeler can be a very effective tool as it provides evaluations for various traffic condition conditions (Papageorgiou et al. 2006). The increment in the demand for private transportation will also increase traffic congestion during peak hours (Yahia 2017; Yahia et al. 2017). Additionally, flaws in the public transport system will result in longer waiting time (delay), and also very little headways between vehicles, particularly in the city of Nicosia, Northern Cyprus. The number of vehicles registered in Nicosia, Northern Cyprus was up 4.5\% in 2015 compared to 2013 over 175982 vehicles. According to the state planning organization, statistics and research department Nicosia in 2017 the number of registered vehicles increase nearly $66 \%$ compared with 2015 , including registered vehicles around 182709 and none-registered vehicle approximately 109665 (Statistics and Research Department, Nicosia 2017). Therefore, with those huge numbers of vehicles on the road, the responsible authorities for the roads are required to develop tidal traffic capacity by controlling and estimating the future growth of traffic movement as well as to find out appropriate solutions to prevent the overcrowding of traffic congestion on intersections and roundabouts (Akçelik et al. 1999). These will be done using intelligent software called SIDRA INTERSECTION 5 which is "a micro-analytical traffic evaluation tool that employs lane-by-lane and vehicle drive cycle models" (Irtema et al. 2015). Its function is to compare different treatments of separate intersections as well as networks of intersections involving signalized and un-signalized intersections roundabouts.

The performance of traffic flow in Kuala Lumpur and Petaling Jaya was evaluated using SIDRA INTERSECTION 4, it showed a reduction in the average delay and fuel consumption while increasing the travel speed. A significant reduction was also observed from the results that the traffic flow at the intersections and roundabouts managed to be optimized (Albrka et al. 2014). This study aims to evaluate the existing traffic flow system at signalized four intersections and two roundabouts in busy areas in Nicosia (northern part of the island) and establish a comparative study between the morning and evening peak hours.

\section{METHODOLOGY AND STUDY AREA}

The study focused on traffic flow at signalized intersections and roundabouts, to evaluate the current situation of traffic system in the city. The performance of the traffic flow was analyzed and assessed using SIDRA INTERSECTION 5 Software. Also, after the observation and site selection, the parameter was collected for the field, namely, the volume of traffic including (cars, motorcycles, van, trucks, and buses), phases movement of intersections with the cycle time and the geometric design of intersections. The volume of traffic, which the most critical factor when it was collected, must be collected during regular working days besides avoiding severe weather conditions and natural traffic conditions when accidents occur. 
Otherwise, it will result in fake traffic volume collections at the intersections. Moreover, the data were collected for 15 minutes in the morning and evening peak hours, whereby the peak hours were observed between 8:15-9:00 am in the morning and between 4:00-5:30 p.m. Cyprus is the third biggest island in the Mediterranean Sea regarding the area. The island was divided, and there have been two de-facto areas (Northern and Southern) since 1974. Nicosia is the capital city of Cyprus. It is the only divided capital city in the world. It has northern and southern sections. A case study is chosen for the north part of Nicosia, also known as Lefkoşa.

The north Nicosia has a total population of 94824, where around one-third of the northern part whole population lives, according to the latest census which was performed in 2011 (Statistics and Research Department Nicosia 2017). The study considered regions of the most important urban area in the city regarding it busy traffic which causing traffic congestion during morning and evening peak hours. 4 signalized intersections and two roundabouts were selected after several field visits to all regions to choose the most appropriate intersections to experience traffic congestion.

\section{GEOMETRIC DESIGN OF FIELD STUDY}

The geometric design and locations of the intersections and roundabouts of the field study are shown in Figures (1-6). The dimensions of cross-section elements of the roads such as shoulders of intersections, medians, the width and length of the lanes and the traffic lights were collected from the field of study to ensure that the design and simulation using SIDRA INTERSECTION 5 are identical to the reality. In the process of optimization and improve the level of service in the traffic flow at intersections and roundabouts should be performed using SIDRA INTERSECTION 5 software.

There are three steps to enhancing the level of service at junctions and roundabouts. The steps namely, adding new phases movement, giving way (slip lane) for the vehicle turn to the left and increasing the capacity of the road by increasing the width of shoulders to estimate the massive amount of traffic flow at intersections and roundabouts during peak periods (Irtema et al. 2015).

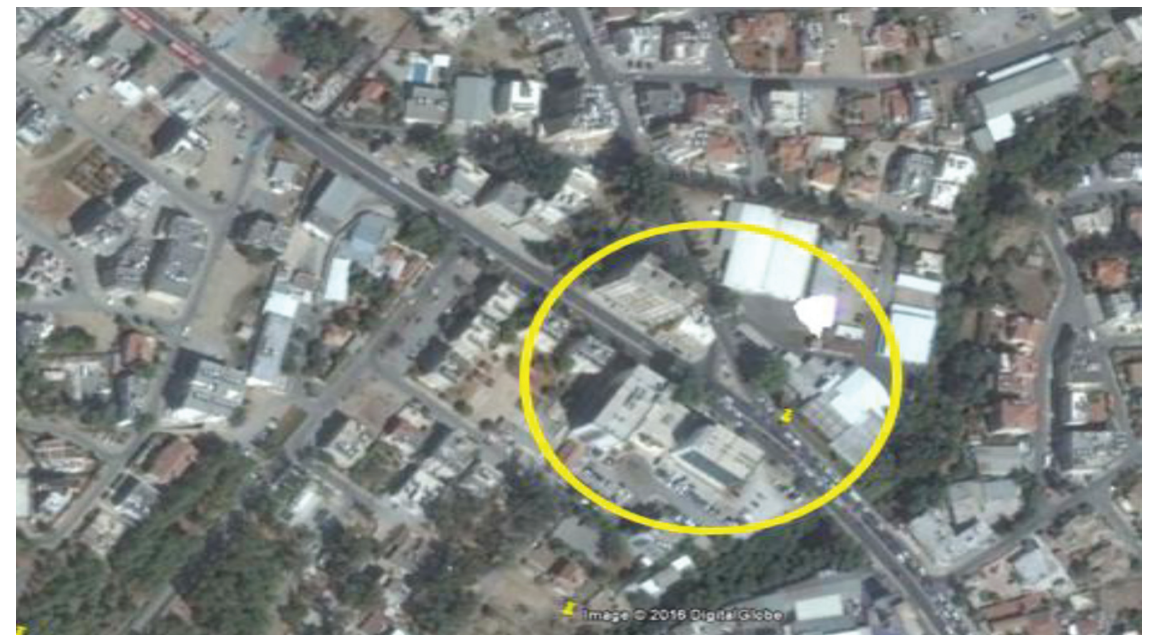

FIGURE 1. Location of three legs intersection (Google Map 2017)

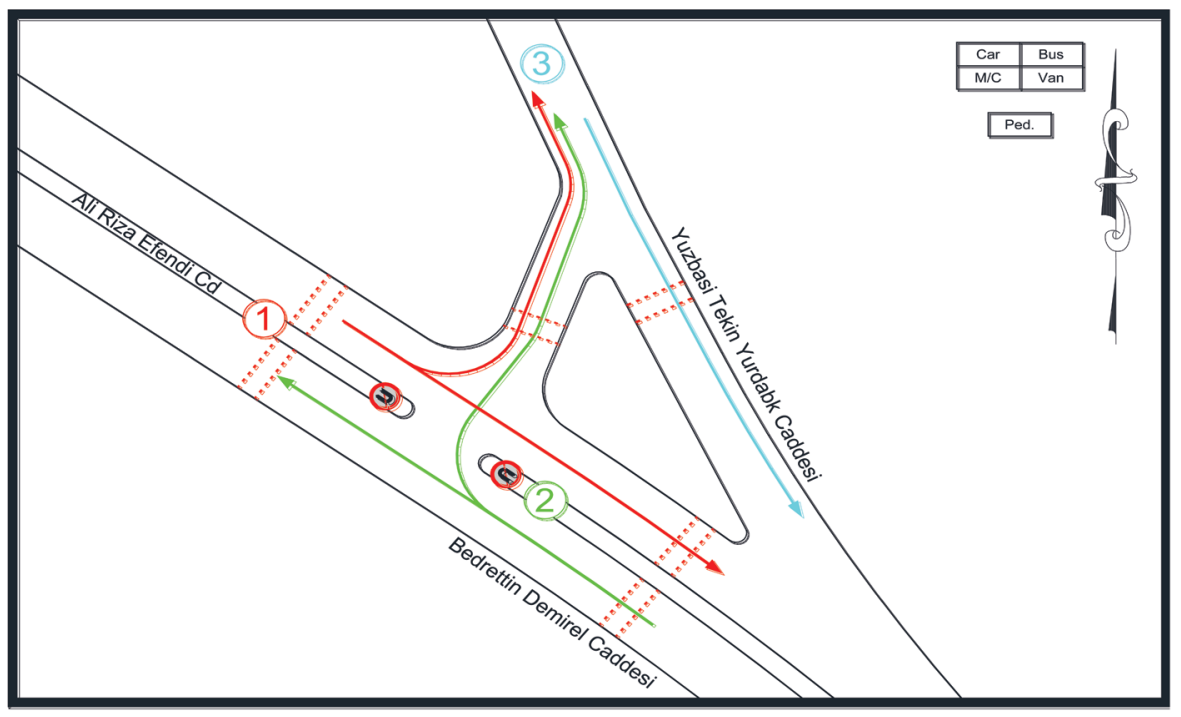

FIGURE 2. Geometric design of three legs intersection 


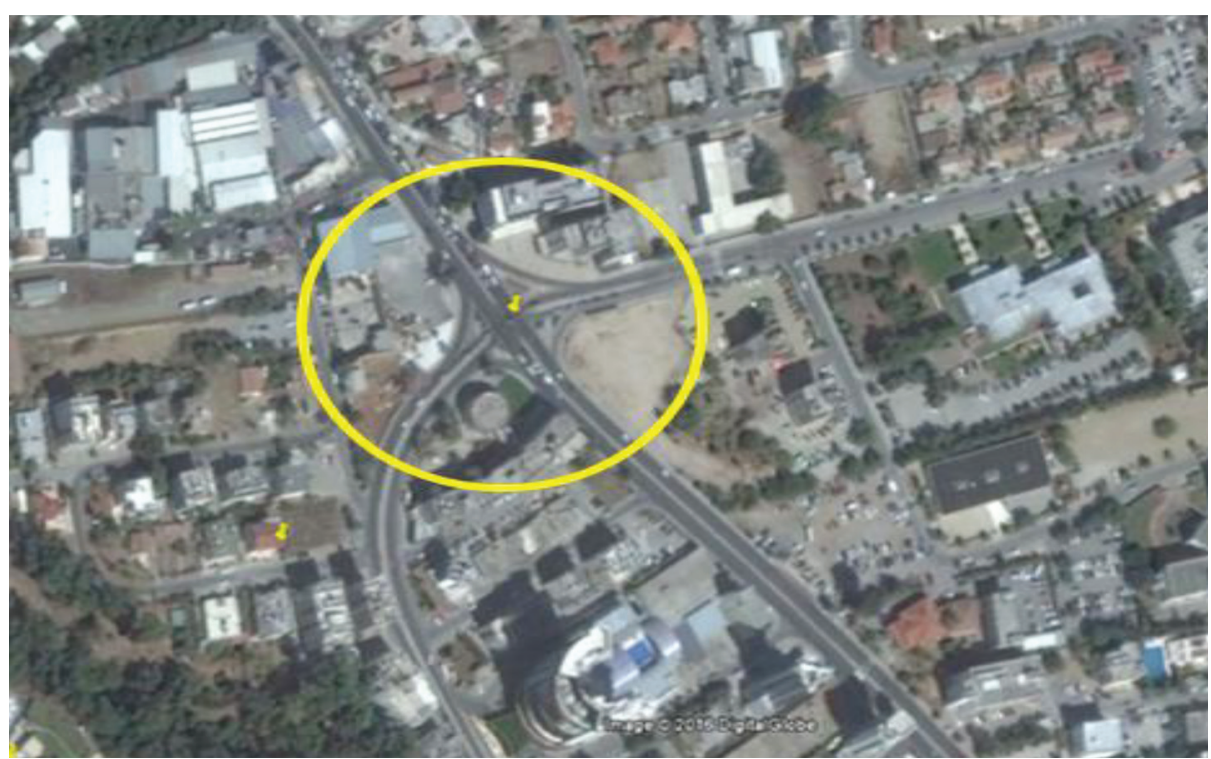

FIGURE 3. Location of four legs intersection (Google map 2017)

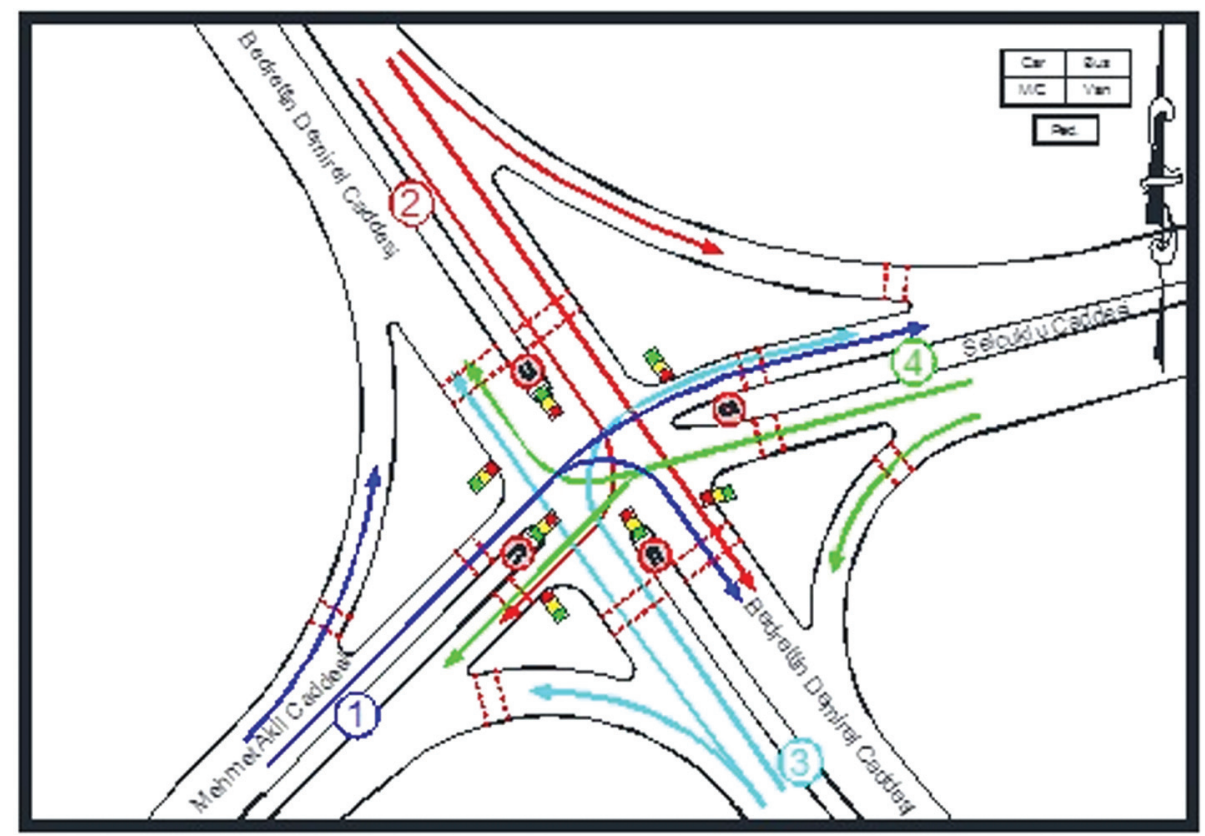

FIGURE 4. Geometric design of four legs intersection

\section{RESULTS AND DISCUSSION}

The occurrences of traffic congestion in urban areas have noticeably posed some severe problems to drivers especially during the peak hours, whereby significant effects are felt on the land use, driver's behavior and the economy. Besides that, it also reduces the travel speeds primarily because the number of vehicles is too high for the available road capacity, and this makes travel times longer and increases the queueing. Several solutions were applied to the congestion to combat this problem either by re-coordinating the cycle time of intersection according to the volume of traffic flow in morning and evening or increasing the capacity of the road at the areas of intersections, whereby the latter is not favorable as it is the high-cost solution. As a result, the following sections discuss the results of the existing situation of traffic flow which was evaluated by SIDRA INTERSECTION 5 software excluding the optimization process.

\section{AVERAGE DELAY}

The difference in the arrival and departure time of a vehicle at the intersection is known as the delay at a signalized intersection. It is also recognized as the extra time spent by a vehicle at the intersection more than required if the vehicles were allowed to pass the intersection without any interruptions. Therefore, the delay time can be classified into three types namely, acceleration delay, stopped delay and 


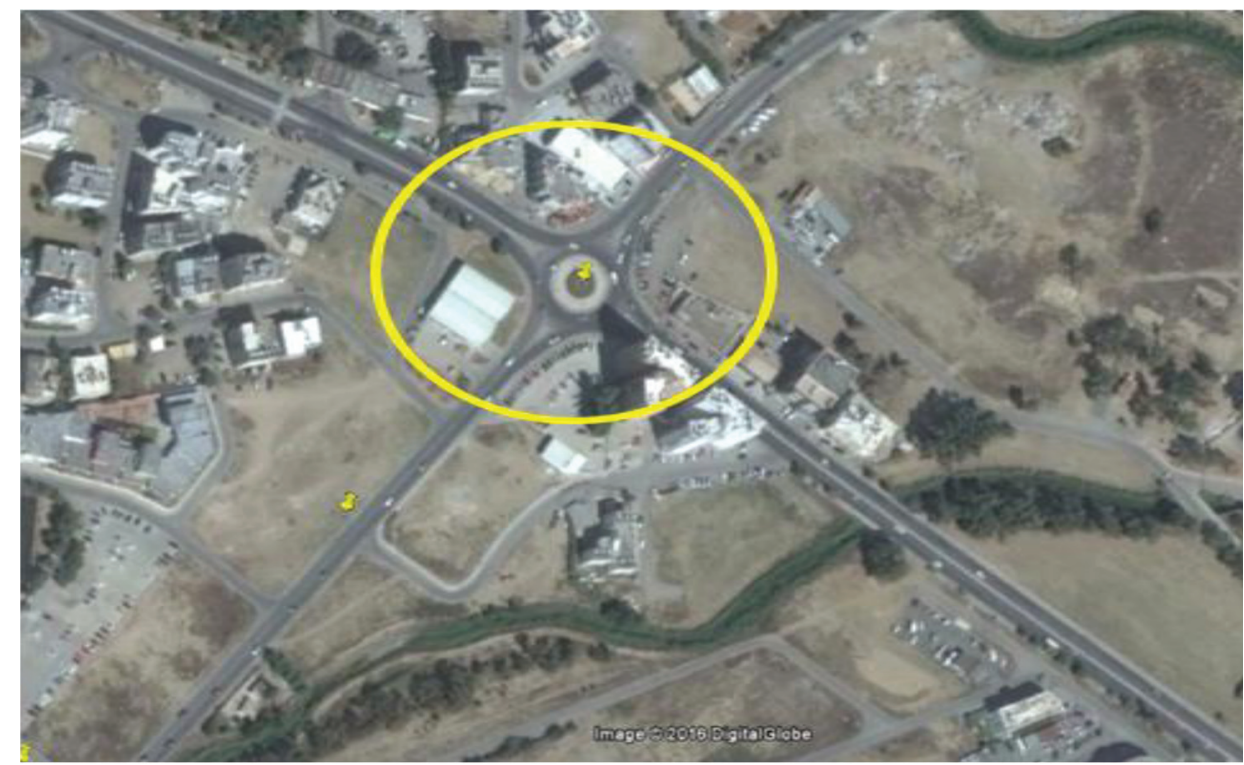

FIGURE 5. Location of roundabout (Google map 2017)

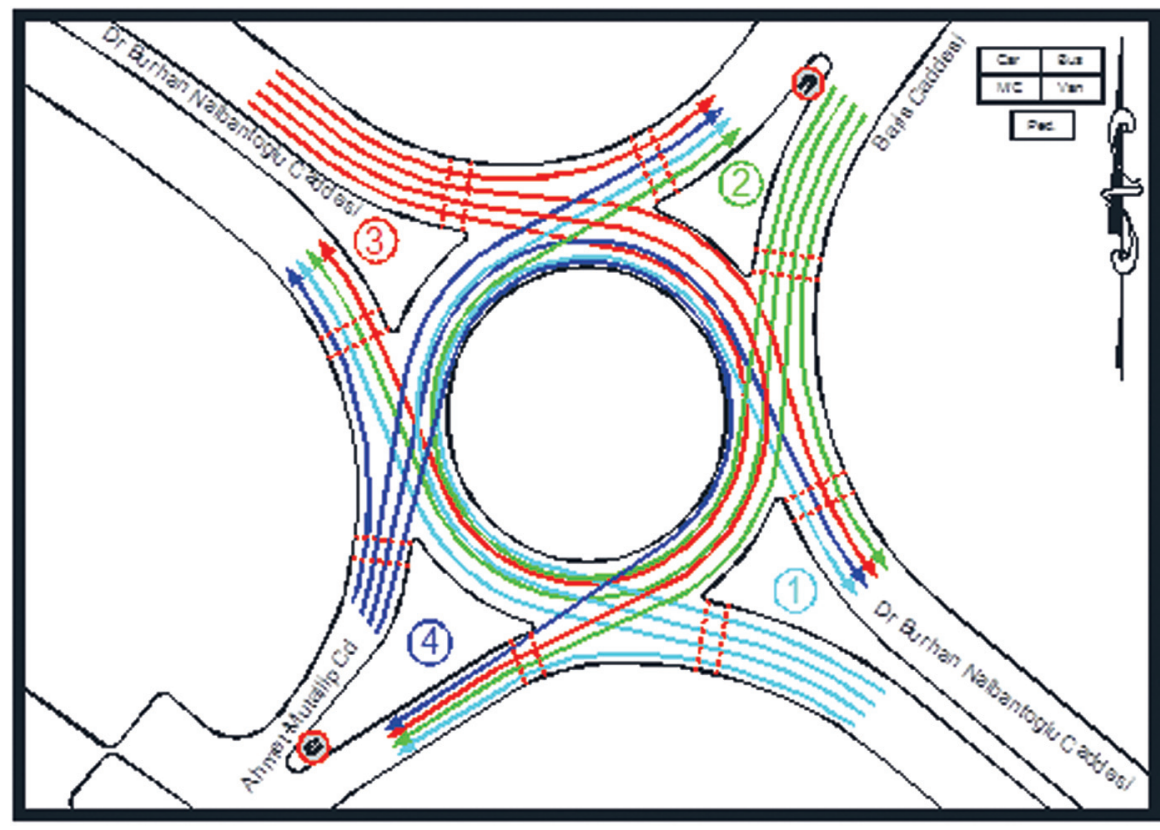

FIGURE 6. Geometric design of the roundabout

deceleration delay. The first thing that most drivers consider when it comes to a traffic jam on roadways is the time (delay). In the morning period, there is additional stress as delays caused by traffic jam lead people to reach their destinations late. Also, the evening rush hour is another frustrating time in the traffic jam because the time to reach residential areas from the work areas is delayed.

Figure 7 shows the results obtained from the field study, whereby the delay was very high in the morning compared to evening peak hours for three and four legs intersections. This due to the simultaneous movement of drivers to their desired destinations (work zones) in the morning, while in the evening, the delay was less severe because of the variety in the movement of people to reach their residential areas.
The reduction was up to $74 \%$ for three and $14 \%$ four legs intersections, respectively. Meanwhile, the travel speed corresponding to the delay in evening peak hour's period is considered better than in the morning for ROA 1 . The evaluation of changes in the speed between morning and evening peak hours were up to $74 \%, 14 \%$ and $62 \%$ for three and four legs intersections and roundabout, respectively.

\section{TRAVEL TIME FOR THE TRIP}

The travel time of the trip is known as the difference between the drivers' predictable travel time through any roadway segments such as intersections or roundabouts and the actual time that was taken. The travel time was given lane by lane 


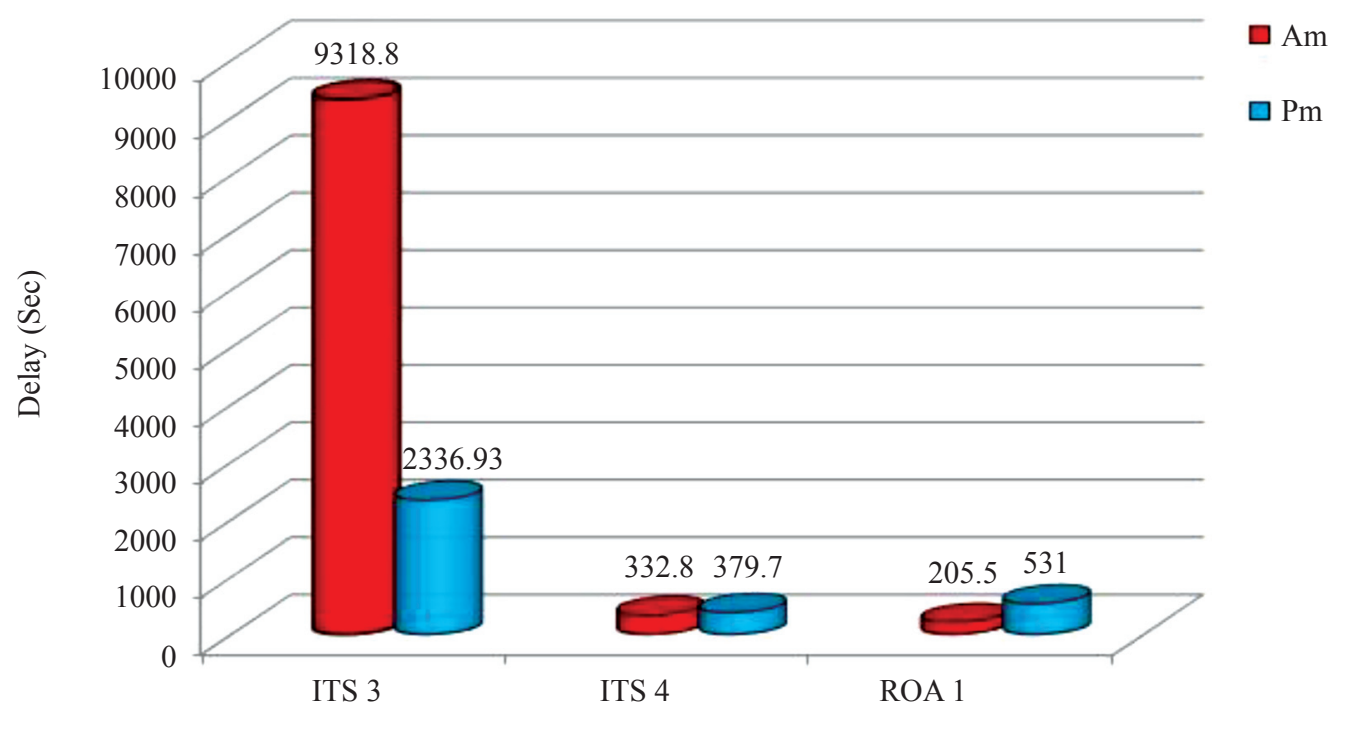

FIGURE 7. Average delay of the study area

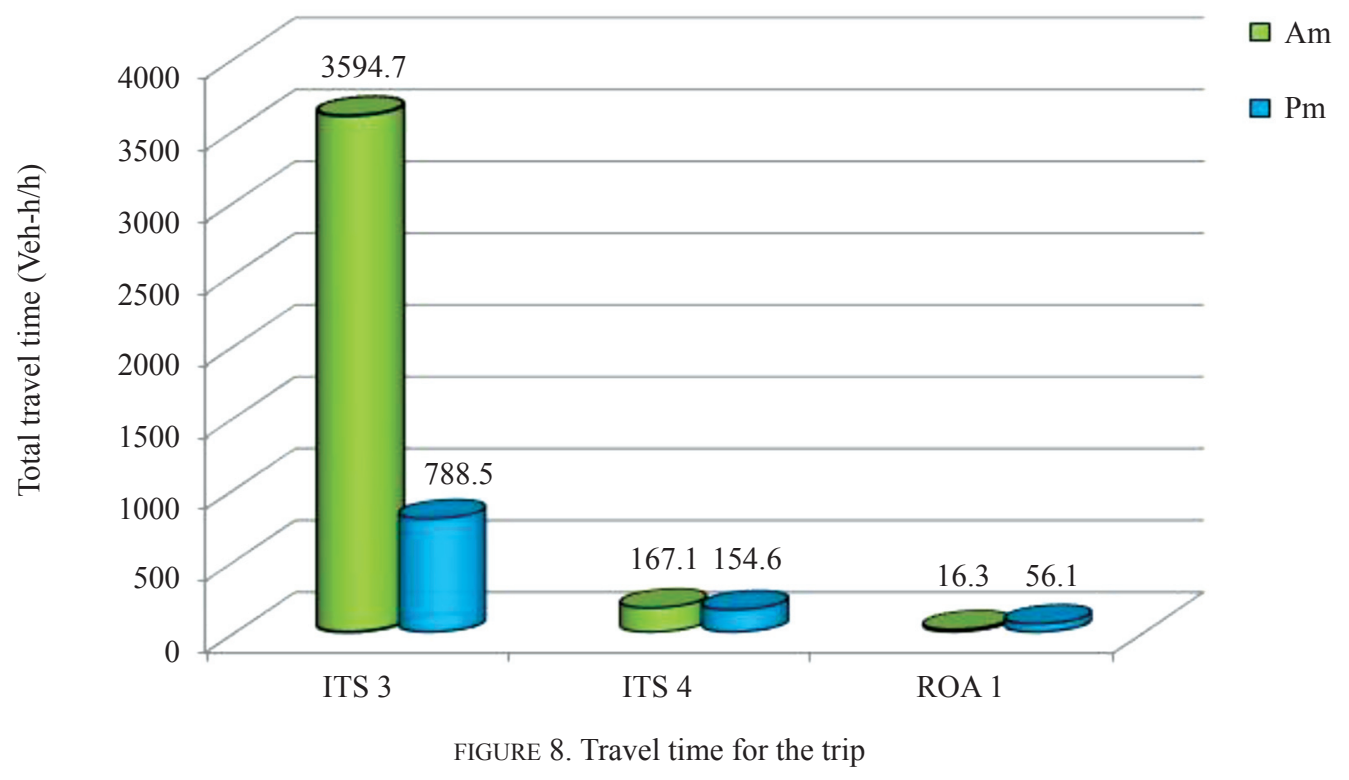

in the SIDRA application; therefore, the delay was measured for the entire phases of an intersection. The results in Figure 8 shows that the total volume of travel time from the intersections and roundabouts. As expected, the travel time in the morning is more than in the evening peak hours, because the travel time has a positive correlation with the average delay. The difference between the morning and evening peak hours was decreased by $78 \%$ for ITS 3 and nearly $7 \%$ for ITS 4 , while it was for increased for ROA 1 by almost $244 \%$. This indicates that the traffic flow in the morning is worse than in evening peak hours. It was also observed that most of the roundabouts in the city have large capacities compared to the intersections.

\section{TRAVEL SPEED OF THE TRIP}

Travel speed during the weekdays both in the morning and evening peak hours in Nicosia has a significant difference from the non-peak periods. The speed of any trip offers a more comfortable journey for the drivers and affects their behavior on the road networks. Evaluation of the current situation's travel speed system using SIDRA INTERSECTION 5 in Figure 9 shows that the movements of vehicles were languidly resulting in traffic congestion at the intersections. It was observed that the speed system in the evening peak hours was better than in the morning periods, in line with the percentage decrease of delay and travel time in evening peaks hours.

Assessment of the current system speed in the city shows that the ITS 3 has $154.6 \mathrm{~km} / \mathrm{h}$ and $169.8 \mathrm{~km} / \mathrm{h}$ with an increase $9.8 \%$ for AM and PM, respectively. Meanwhile, the ITS 4 has a travel speed of $120.3 \mathrm{~km} / \mathrm{h}$ and $89.5 \mathrm{~km} / \mathrm{h}$ with a reduction of $245 \%$ between $\mathrm{AM}$ and $\mathrm{PM}$, respectively. Also, the ROA 1 has a travel speed of $16.3 \mathrm{~km} / \mathrm{h}$ and $56.1 \mathrm{~km} / \mathrm{h}$ with the improvement of $244 \%$ between morning and evening peak hours. These differences were due to that the SIDRA 


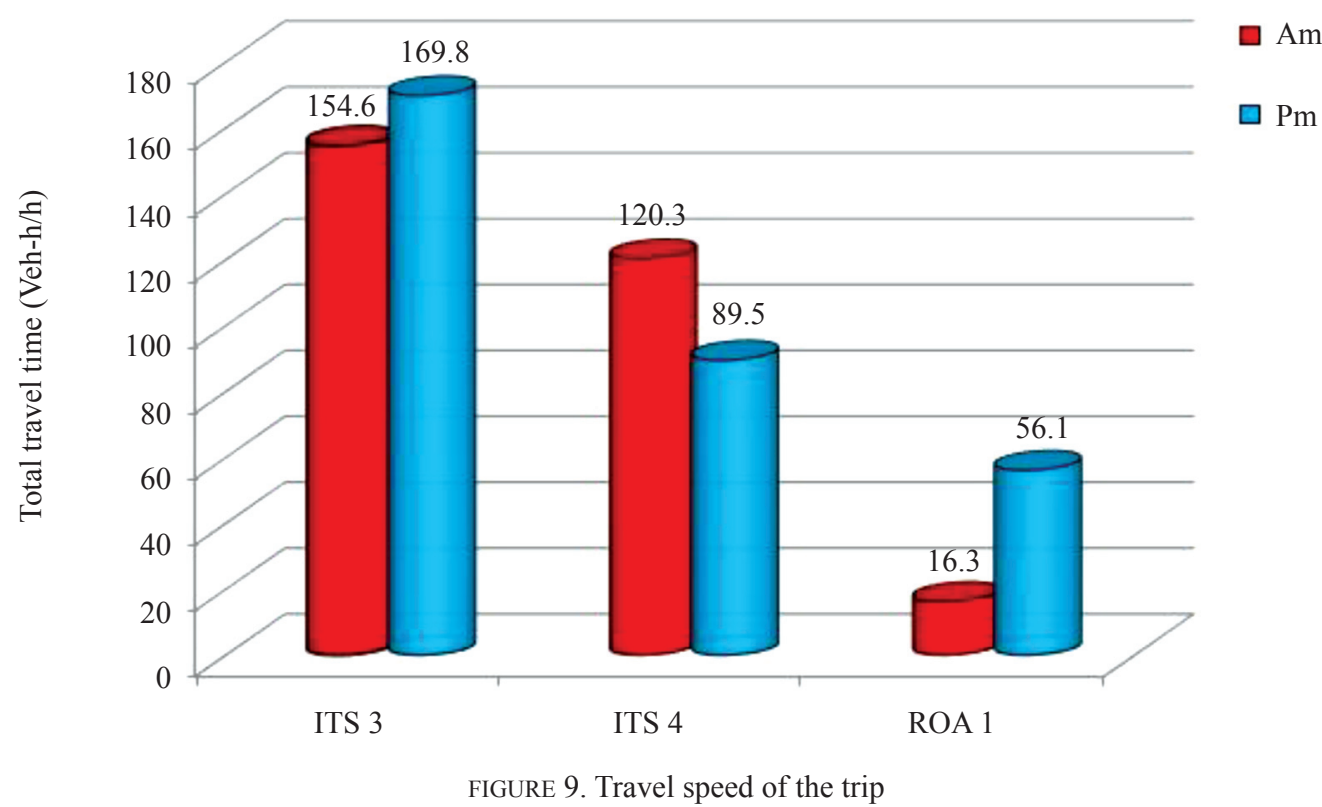

INTERSECTION 5 application evaluated each intersection and roundabout individually. Figure 10 indicates the average fuel consumption rate of the deceleration and acceleration of vehicles at the intersections. The ratio of acceleration operation at intersections and roundabouts has significant effects on the total fuel consumption during the trip. When the acceleration occurs, the engine prerequisites more fuel to produce power resulting to the increment on the rates of fuel consumption. It was noted from Figure 10 that the rate of fue consumption in ITS 3 is nearly 1431.6 for AM and 313.9 for PM with a reduction of $78 \%$ those between the peak hours. Moreover, for ITS 4 the rate was $66.5 \mathrm{AM}$ and $61.4 \mathrm{PM}$ with a decrease of $7 \%$, while for the roundabout, it was $55.1 \mathrm{AM}$ and $531 \mathrm{PM}$ with an increment of $863 \%$. It was clear that the morning peak hours were subjected to delay more than evening peak hours.

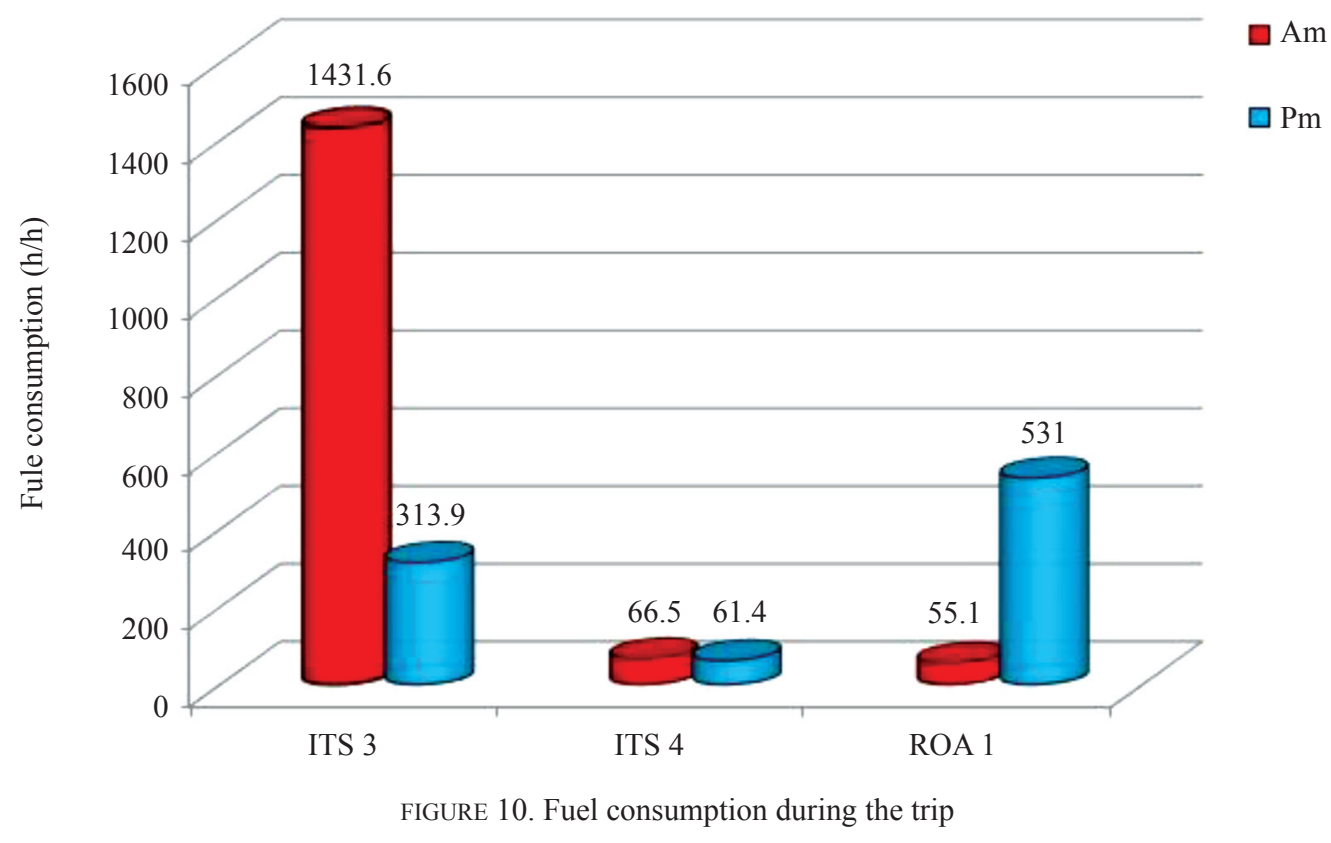

OPERATING COST AND $\mathrm{CO}_{2}$ EMISSIONS

The usage of vehicle parameters such as; fuel, oil and tire maintenance are known as the most common operating costs of a vehicle. The element that affects the operating costs of any vehicle depends on the increment of the total travel time of the trip as the operating cost will be increased as well besides the delay at intersections and roundabouts. Figure 11 indicates the operating cost of the vehicles in the selected study areas. The results show that the operating costs if both intersections three and four legs in PM peak hours were reduced compared to in AM. The reduction was up to $32.25 \%$ and $18.61 \%$, respectively, while the ROA 1 shows a different 


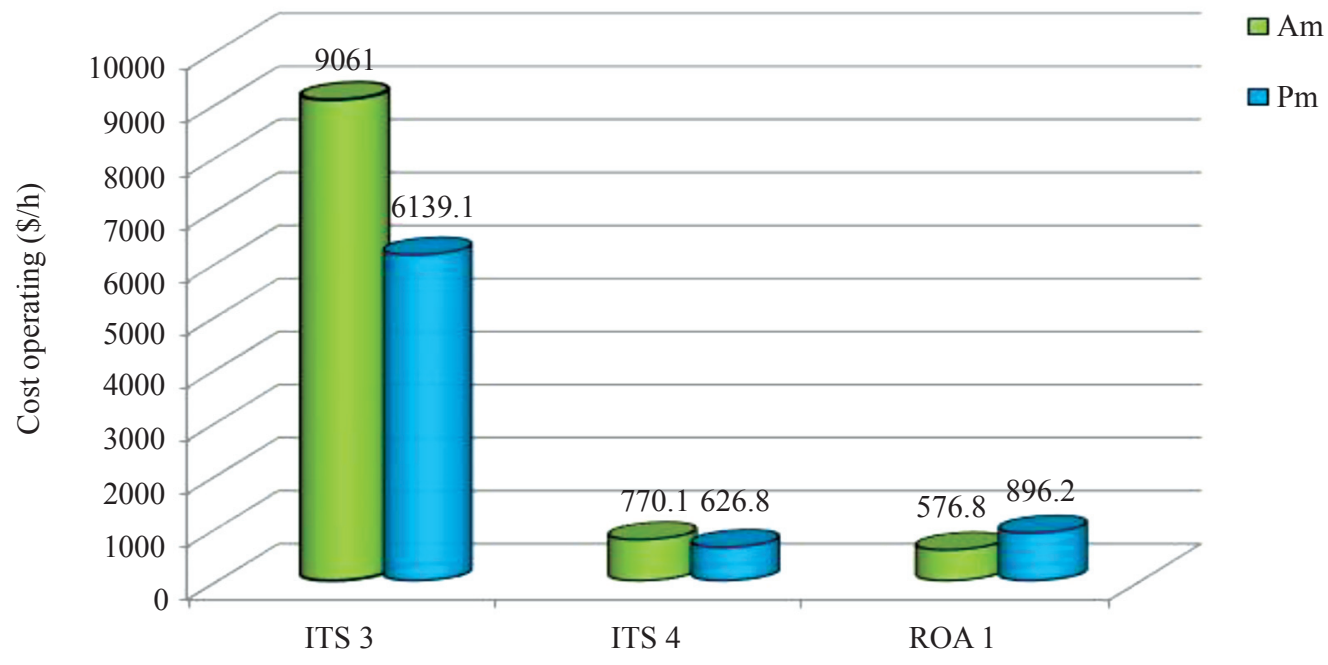

FIGURE 11. Operating cost during the trip

behavior as the operating costs were increased in PM period more than in AM. This indicates that the roundabout in the evening has a better level of service and less delay compared to morning rush hours. The volume of $\mathrm{CO}_{2}$ generated from the burning of fuel depends on the quantity of carbon in the fuel. The combustion of fuel in the vehicles depends on the total travel time of the trip, speed, and delay which all depend on the traffic condition. From Figure 12, it can observe that a high amount of $\mathrm{CO}_{2}$ was produced at ITS 3 as the level of service indicates of a lot of stops and delay at intersections, especially in morning peak hours.

\section{LEVEL OF SERVICE (LOS)}

The signalized intersection level of service (LOS) is defined regarding the average total vehicle delay of all movements through an intersection (Highway Capacity Manual 2000). Vehicle delay is a technique of measuring some intangible factors, including loss of travel time as well as drivers' discomfort and frustration. The vehicles' delay is a complex parameter to measure, and it depends on several variables such as signal cycle length, signal phasing, and traffic volumes concerning the capacity of intersections and roundabouts. Table 1 shows LOS of a signalized intersection, as defined in the SIDRA INTERSECTION 5 user guide (Highway Capacity Manual 2000).

TABLE 1. Level of Service (LOS) criterion for signalized intersection (Akcelik 2010)

\begin{tabular}{cccc}
\hline \multirow{2}{*}{ LOS } & \multicolumn{3}{c}{ Control delay per vehicle in Seconds (d) } \\
\cline { 2 - 4 } & Signalized & Roundabouts & Stop and Giveaway/yield \\
\hline A & $\mathrm{d} \leq 10$ & $\mathrm{~d} \leq 10$ & $\mathrm{~d} \leq 10$ \\
$\mathrm{~B}$ & $10<\mathrm{d} \leq 20$ & $10<\mathrm{d} \leq 20$ & $10<\mathrm{d} \leq 15$ \\
$\mathrm{C}$ & $20<\mathrm{d} \leq 35$ & $20<\mathrm{d} \leq 35$ & $15<\mathrm{d} \leq 25$ \\
$\mathrm{D}$ & $35<\mathrm{d} \leq 55$ & $35<\mathrm{d} \leq 50$ & $25<\mathrm{d} \leq 35$ \\
E & $55<\mathrm{d} \leq 80$ & $50<\mathrm{d} \leq 70$ & $35<\mathrm{d} \leq 50$ \\
F & $80<\mathrm{d}$ & $70<\mathrm{d}$ & $50<\mathrm{d}$ \\
\hline
\end{tabular}

The results show that the level of service in field study was on $\mathrm{F}$ level for both periods for ITS 3 , which means the delay rate is very high (jammed or traffic is blocked), while it is D and C for ITS 4 whereby the delay is acceptable on $\mathrm{C}$ level. It was $\mathrm{B}$ and $\mathrm{E}$ for ROA 1. This indicates that the traffic flow in the city is hugely congested and economical solutions should be incorporated into the matter to avoid the traffic congestion at peak hours in the city. The economic solutions that can improve and enhance the traffic flow along the intersections and roundabouts are re-coordination of signals (cycle time) according to the volume of traffic, given slipways for the left movements and increment the shoulders of intersections. The level of service in the field study is listed in Table 2.

TABLE 2. LOS of study area (AM and PM)

\begin{tabular}{cccc}
\hline $\begin{array}{c}\text { No of } \\
\text { intersection }\end{array}$ & $\begin{array}{c}\text { LOS } \\
\text { before }\end{array}$ & Delay & $\begin{array}{c}\text { The rate of changes (\%) } \\
\text { Between AM \&PM }\end{array}$ \\
\hline ITS 3 AM & F & 9318.8 & $75 \%$ \\
ITS 3 PM & F & 2336.9 & \\
ITS 4 AM & D & 332.8 & $14 \%$ \\
ITS 4 PM & C & 379.7 & \\
ROA 1 AM & B & 205.5 & $62 \%$ \\
ROA 1 PM & E & 531 & \\
\hline
\end{tabular}

\section{CONCLUSIONS}

It is necessary to generate a model among the most significant components of the traffic flow, such as the; traffic volume, density, speed and the drivers to design and control a good transportation system. The delay comprises loss of time due to low speed, lots of stops and deceleration in the movement of vehicles. The present study was conducted to evaluate the sufficiency of the traffic flow in the city of Nicosia and the results obtained from the SIDRA INTERSECTION 5 software demonstrate a clear indication that the city suffers from severe 
traffic congestion during peak hours. This congestion is due to the low capacity of the road which consists of only two lanes. Furthermore, the cycle time at the intersections is typically established with appropriate calculations of traffic volume, but it seems that it was mostly assigned based on experience. As the working hours in the morning and evening are the same for the most of the employees, it is quite impossible to reduce the demand during peak hours. Working hours should be staggered and varied to shift the temporal distribution of the demand; then only the peak period load can be reduced; therefore, resulting to more efficient use of capacities on the road system.

\section{ACKNOWLEDGEMENT}

The authors would like to thank the students of the special project (transportation) for helping of data collection in the city of Nicosia. Also, the authors acknowledge Faculty of Engineering at Near East University for providing facilities.

\section{REFERENCES}

Akcelik, R. 2010. SIDRA Intersection 4.0 User Guide. Akcelik \& Associates Pty Ltd., Greythorn, Australia.

Albrka, S.I., Ismail, A., Yahia, H.A. \& Ladin, M.A. 2014. Application of transyt-7f on signalized road junction networks in Shah Alam and Petaling Jaya. Jurnal Teknologi 69(2): 59-64.

Google map 2017 [15/04/2017].

Irtema, H.I.M., Ismail, A., Albrka, S.I., Ladin, M.A. \& Yahia, H.A. 2015. Evaluating the performance of traffic flow in four intersections and two roundabouts in Petaling Jaya and Kuala Lumpur using Sidra 4.0 software. Jurnal Teknologi 72(4): 1-5.
Highway Capacity Manual. 2000. Washington, DC.

Papageorgiou, G., Damianou, P., Pitsillides, A., Aphames, T. \& Ioannou, P. 2006, July. A microscopic traffic simulation model for transportation planning in Cyprus. In International Conference on Intelligent Systems And Computing: Theory And Applications (ISYC).

Statistics and Research Department Nicosia. 2017. Turkish Republic of Northern Cyprus Statistical Yearbook.

Yahia, H.A. 2017. Development of Roundabout Delay Models Using Traffic Simulation Programs: A Case Study at Al-Mansour City, Iraq. Jurnal Kejuruteraan 29(2): 97-103.

Yahia, H.A., Safinia, S., Al Musharfi, N.K. \& Ali, S.S. 2017

Car Driver Attitude towards Road Safety Measures. Jurnal Kejuruteraan 29(1): 57-61.

*Shaban Ismael Albrka Ali

Rifat Reşatoğlua

Hudaverdi Tozan

Civil Engineering Department

Faculty of Engineering

Near East University

Nicossia, North Cyprus,

Turkey.

*Corresponding author; email:

shabarofking10@gmail.com

Received date: $13^{\text {th }}$ January 2018

Accepted date: $27^{\text {th }}$ March 2018

Online First date: $1^{\text {st }}$ September 2018

Published date: $31^{\text {st }}$ October 2018 